\title{
Article \\ Experimental Study of the Effects of Torsional Loading on Three Types of Nickel-Titanium Endodontic Instruments
}

\author{
Andreea-Simona Boscornea-Pușcu ${ }^{1,+}{ }^{,}$Laura Orel ${ }^{1}$, Oana-Alexandra Velea-Barta ${ }^{2, *} \mathbb{0}$, Razvan Mihai Horhat ${ }^{2}$,

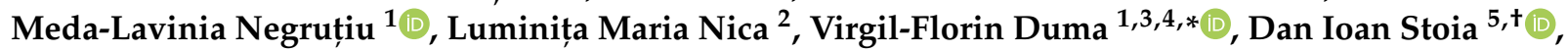 \\ Carmen Opriș ${ }^{6}$ and Cosmin Sinescu ${ }^{1} \mathbb{D}$
}

Citation: Boscornea-Pușcu, A.-S.; Orel, L.; Velea-Barta, O.-A.; Horhat, R.M.; Negrutiu, M.-L.; Nica, L.M.; Duma, V.-F.; Stoia, D.I.; Opris, C.; Sinescu, C. Experimental Study of the Effects of Torsional Loading on Three Types of Nickel-Titanium Endodontic Instruments. Appl. Sci. 2021, 11, 7224. https://doi.org/10.3390/ app11167224

Academic Editor: Gianluca Gambarini

Received: 3 July 2021

Accepted: 3 August 2021

Published: 5 August 2021

Publisher's Note: MDPI stays neutral with regard to jurisdictional claims in published maps and institutional affiliations.

Copyright: (c) 2021 by the authors. Licensee MDPI, Basel, Switzerland. This article is an open access article distributed under the terms and conditions of the Creative Commons Attribution (CC BY) license (https:/ / creativecommons.org/licenses/by/ $4.0 /)$.
1 Research Center in Dental Medicine Using Conventional and Alternative Technologies, School of Dental Medicine, "Victor Babeș" University of Medicine and Pharmacy of Timisoara, 9 Revolutiei 1989 Ave., 300070 Timișoara, Romania; simonapuscu@gmail.com (A.-S.B.-P.); orel.laura@umft.ro (L.O.); medanegrutiu@gmail.com (M.-L.N.); minosinescu@gmail.com (C.S.)

2 3rd Department of Odontotherapy and Endodontics, Faculty of Dental Medicine, "Victor Babeș" University of Medicine and Pharmacy, 300041 Timișoara, Romania; razvanhorhat@yahoo.com (R.M.H.); luminita.nica98@yahoo.ro (L.M.N.)

3 3OM Optomechatronics Group, "Aurel Vlaicu” University of Arad, 310130 Arad, Romania

4 Doctoral School, "Politehnica” University of Timisoara, 1 Mihai Viteazu Ave., 300222 Timisoara, Romania

5 Department of Mechanics and Strength of Materials, "Politehnica" University of Timisoara, 1 Mihai Viteazu Ave., 300222 Timisoara, Romania; dan.stoia@upt.ro

6 Department of Materials and Manufacturing, "Politehnica" University of Timisoara, 1 Mihai Viteazu Ave., 300222 Timisoara, Romania; carmen.opris@upt.ro

* Correspondence: velea.oana@umft.ro (O.-A.V.-B.); duma.virgil@osamember.org (V.-F.D.); Tel.: +40-751-511451 (V.-F.D.)

+ These authors contributed equally to this work.

\begin{abstract}
In modern endodontics, nickel-titanium (NiTi) rotary instruments are used on a large scale for root canal shaping. Nevertheless, the separation of an instrument is a serious concern during shaping. The aim of this study is to determine and compare the torsional fracture characteristics of three types of NiTi endodontic instruments, each with different cross-section designs and movements performed during root canal shaping: Endostar E3 (Endostar, Poldent Co. Ltd., Warsaw, Poland); Reciproc R25 (VDW, Munich, Germany); and Protaper Next X2 (Dentsply Maillefer, Ballaigues, Switzerland). Fifteen instruments are used in this study, divided in three groups $(n=5)$ : Group Endostar, Group Reciproc and Group Protaper. For testing, each instrument is used to shape five simulated root canals, following which its torsional stress to failure is measured. The fracture lengths of all three groups are roughly between 2 and $3 \mathrm{~mm}$ from the tip. Higher values of the moment of torsion in fracture, and smaller values of the maximum twisting angle are observed for Group Endostar, as well as closer to circular cross-sections. However, the values of the shear tension are similar for all three groups, because the disadvantage given by the fracture section shape for Groups Reciproc and Protaper is compensated either by size or by intrinsic properties of the instrument material. For the shear tension the Endostar values are insignificantly increased (Kruskal-Wallis test, $p=0.207)$, and in the case of the maximum twist angle the Protaper values are insignificantly increased (Kruskal-Wallis test, $p=0.287$ ). Because of the instruments shape and conicity, the analysis had to be carried out separately with regard to the length of the fractured tip. Rules-of-thumb are extracted from the study for current practice: if a blockage of the first 2 to $3 \mathrm{~mm}$ part of the tip can be anticipated (by the excessive curving of the instrument), the handpiece must be adjusted to torque values that do not exceed 1.5 to $2.5 \mathrm{~N} \cdot \mathrm{cm}$ for Endostar and 1 to $2 \mathrm{~N} \cdot \mathrm{cm}$ for Reciproc and Protaper instruments.
\end{abstract}

Keywords: nickel-titanium (NiTi) instruments; endodontic instruments; torsional fracture; cleaning and shaping; simulated root canals; instrument separation; cross-section 


\section{Introduction}

In modern endodontics NiTi rotary instruments are used universally for root canal shaping. Compared to conventional stainless-steel files, they are more elastic and have a higher cutting quality. In addition, they allow us to achieve the tapered root canal shape with less canal transportation because of their super-elasticity [1].

Walia et al. first introduced NiTi root canal files to solve the issue of the rigidity of stainless-steel instruments and thus, to improve the preparation of curved root canals [2]. However, unexpected fracture of NiTi rotary instruments during their use (i.e., inside the tooth) remains a current problem and has a negative influence on the treatment outcome [3-7]. Three different ways have been described in the literature regarding the causes for which NiTi instruments tend to fracture: due to torsion, to flexural fatigue [8-10], or to a combined mechanism of flexural and torsional stress [11]. Flexural fatigue appears to be more common in curved root canals, while torsional failure can occur in a straight root canal [12-14].

An ideal mechanical preparation of the endodontic space has a continuous tapered shape along the entire length of the root canal, from the coronary level to the apical third, respecting the anatomical shape and the multi-planar curves of the canal, while mantaining the size of the foramen as small as possible [15]. This desideratum is still a major challenge in current clinical practice, in terms of narrow and curved root canals [16]. When the tip or another component of the instrument gets stuck in the root canal as the shank continues to rotate, an overload torsional fracture occurs [8]. If the torque generated by the handpiece reaches the elastic limit of the metal, fracturing of the tip becomes unavoidable [17]. Instruments fractured due to torsional loads show elements of plastic deformation that occur prior to failure [8].

These issues have led to the introduction of M-wire alloys as revolutionary systems that have higher resistance to cyclic fatigue compared to conventional NiTi instruments $[18,19]$. Thus, in 2007 a patented thermomechanical manufacturing process was created by (Sportswire LLC, Langley, OK, USA), aimed to produce a more flexible NiTi alloy with improved cyclic fatigue resistance [20]. This resistance is linked to several characteristics of endodontic files, including diameter, flexibility of the file, metal density, regressive surface area, crosssectional shape, and presence of transitional zones in these files [21]. How to chose between the various types of NiTi endodontic instruments on the market today, each with its own cross-sectional shape that behaves differently on stress distribution and fracture tendency? This is a question at which this study aims to contribute for an answer. Thus, four crosssectional shapes can be found: convex triangle, triangle, rectangular, and parallelogram [22]. They are important (as studied in this work, as well), because it has been shown for example that stress accumulation under bending conditions of rotary files during preparation of curved root canals can be minimized by using designed rotary NiTi instruments with rectangle centered cross-section configuration, a low pitch, and reduced taper [23].

Studies regarding torsional stress and cyclic fatigue have been performed on many types of rotary instruments, but especially on those made from M-wire alloys, as they are part of the most used systems in current endodontic practice. Two such types of instruments, made from an M-wire alloy are considered in this study: Reciproc R25 (VDW, Munich, Germany) and Protaper Next X2 (Dentsply Maillefer, Ballaigues, Switzerland). Their performances are compared with the Endostar E3 instrument (Endostar, Poldent Co. Ltd., Warsaw, Poland), made out of conventional (i.e., untreated) NiTi. This choice of is due to the fact that for the latter type of instruments few or no studies have been performed so far, to our knowledge, because of its lack of popularity, as it is the most recently introduced on the market. In addition, it is interesting to compare this untreated) NiTi instrument with M-wire alloy-based ones.

The aim of the present work is to study the torsional fracture characteristics of these endodontic instruments manufactured with different techniques. The approach is also different: while previous studies have investigated the characteristics of flexural and torsional resistance of NiTi rotary instruments [24], the present one investigates the resistance 
at torsional stress following the wear of instruments in curved dental canals (where they are subjected to both flexural and torsional stress). This corresponds to real-life situations, where both types of stress are present in processing curved canals, but only torsional stress occurs in processing straight canals. As a methodological advantage, the latter type of stress allows for an easier approach of the behavior of the instruments.

The study hypotheses are: (i) the cross-section of the instruments influences the resistance of the instruments to torsional loading; (ii) the quality of the NiTi alloys improves the flexibility, and therefore, the resistance to fracture by torsional overloading of the instruments.

\section{Materials and Methods}

Fifteen endodontic NiTi instruments were used in this study. They were divided in three groups, each one with an equal number of instruments $(n=5)$, (Figure 1):

- Group Endostar consists of E3 Endostar (Endostar, Poldert Co. Ltd., Warsaw, Poland) instruments.

- Group Reciproc consists of Reciproc R25 (VDW, Munchen, Germany) instruments.

- Group Protaper consists of Protaper Next X2 (Dentsply Maillefer, Ballaigues, Switzerland) instruments.

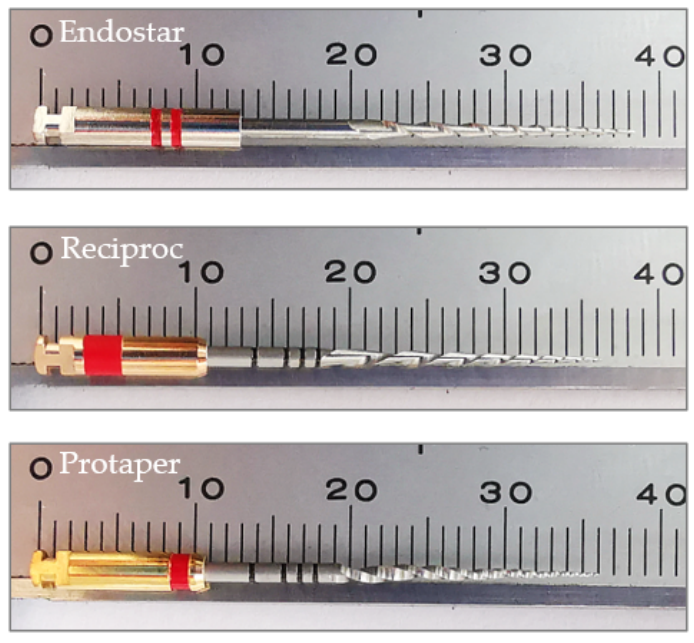

(a)
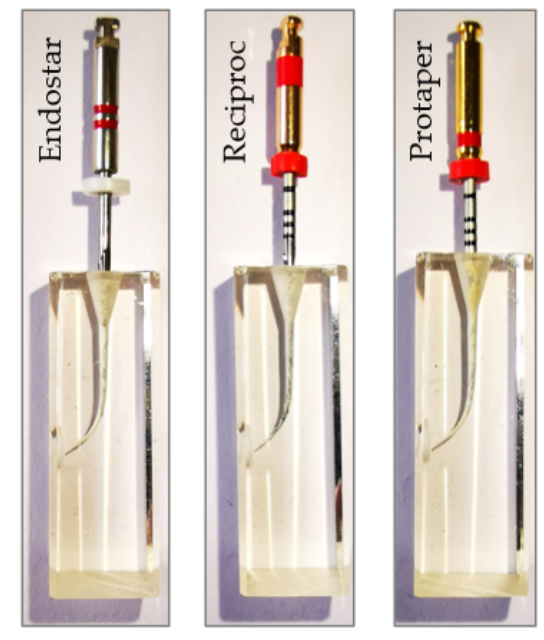

(b)

Figure 1. The three investigated types of NiTi rotary instruments before torsional fracture: (a) measurements of their dimensions; (b) instruments introduced in the simulated root canals. Notations: Endostar, Reciproc, and Protaper stand for the three considered groups.

For the sample size calculus, we conducted a power analysis test with GPower3.1 application using a "Laplace" Parent Distribution, 0.05 level of significance, $80 \%$ power and 1 as an allocation ratio.

Each type of instrument has different shapes of their cross-section (Figure 1a), as well as different movements performed in the root canal. Thus, instruments of Groups Endostar and Protaper use a continuous rotational movement, while instruments of Group Reciproc use a reciprocating movement.

Before preparing the simulated root canals, to establish the testing configuration, all instruments were measured with a Mitutoyo digital caliper with a $0.02 \mathrm{~mm}$ accuracy and with a Mitutoyo micrometer with a $0.01 \mathrm{~mm}$ accuracy (Mitutoyo America, Aurora, IL, USA), to determine the total length and tip diameter, respectively. This approach is based on the fact that, as studied in the literature, assuring repeatability is an issue in the manufacturing of orthodontic wires [25]. In addition, the initial lengths are important to determine the distance from the tip after fracture. 
In general, the tip diameter plays an important role in clinical root access, while the total length determines the access in deep root canals and also the flexibility of the instrument. Their values are presented in Figure 2. The length $L_{1}$ and the tip size $\Phi$ of the instruments are specific for each manufacturer; the deviations of individual instruments are in the range of hundredths of a millimeter, within the accuracy of the measuring systems.

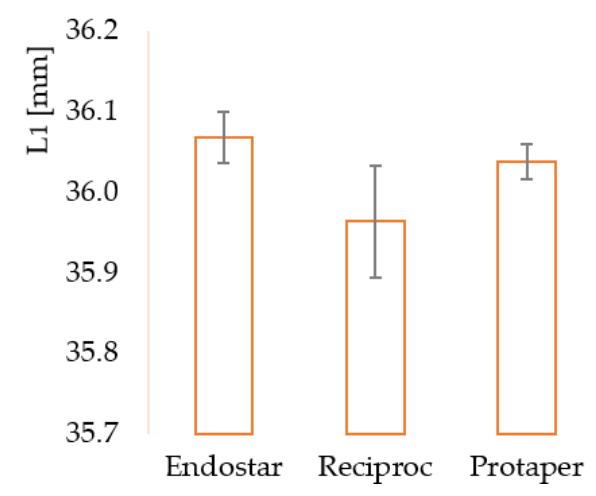

(a)

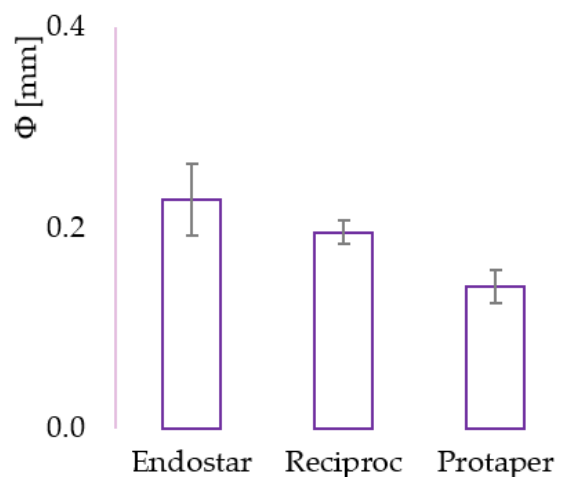

(b)

Figure 2. Dimensions of the considered NiTi rotary instruments: (a) full length $L_{1}(\mathrm{~mm})$ and (b) tip diameter $\Phi(\mathrm{mm})$. Notations: Endostar, Reciproc, and Protaper stand for the three considered groups.

Seventy-five simulated root canals were used for this study [26]. Each of the studied instruments was used to prepare five simulated root canals according to the manufacturer's indications (Figure 1b). Thus, each instrument was subjected to wearing in real-life conditions that (however may) surpass normal endodontic procedures, as such procedures usually imply changing the instrument after even a single preparation, to avoid fracturing it in the next canal.

Following this five-times preparation procedure of each instrument, the torsional stress was measured on each of the five instruments from the three groups using the Mecmesin Vortex $i$ machine (Mecmesin Ltd., Slinford, UK) equipped with a loading cell 0 to $10 \mathrm{Nm}( \pm 0.5 \%)$, under the following conditions: total number of samples, 15; loading velocity, $2^{\circ} \mathrm{s}$; regarding the machine control, the maximum angular displacement was equal to $350^{\circ}$; regarding the fixing of a sample, the driving part of the instrument was placed in the chuck and the tip was placed between its parallel jaws (Figure 3).

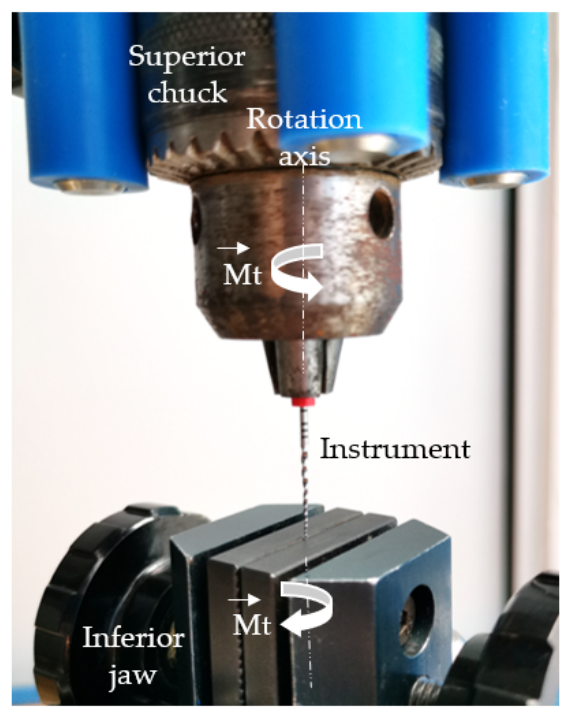

Figure 3. The configuration of the torsion test. 
Each sample instrument was inserted 2 to $3 \mathrm{~mm}$ deep in the parallel jaws, using a template spacer, while the driving end was hold in the chuck by inserting the full cylindrical tail of the instrument. This distance was selected as representing the most common section to fail (i.e., for the instrument tip to get stuck inside a root canal) in clinical practice, because of the anatomical characteristics of teeth. We must remark that a precise insertion of the instrument is actually difficult: the file shape introduces a certain variability, exactly like inside the root canal, when the tip gets stuck at different distances (which are however close, with variations in the submillimeter range).

After fixing each instrument the machine was programmed to turn $350^{\circ}$ in the clockwise direction. The torque value and the angular displacement were recorded by the load cell and the twist counter of the machine.

After the fracture occurred, geometrical and microscopical investigations of the samples were conducted to establish their dimensional characteristics. They were used to calculate the maximum shear stress of each instrument. The microscopic evaluation was performed with an optical microscope Olympus BX51M (Olympus Europa SE \& Co. KG, Hamburg, Germany) at magnifications of $25 \times$ and $50 \times$, necessary to assess the overall aspect of the tip of the instrument and the cross-section aspect after torsional failure, respectively.

\section{Results}

The remaining lengths of the instruments and the extreme values of the dimensions of their transversal sections were measured after fracture using the same type of digital caliper and micrometer (as for the initial values), respectively (Figure 4).

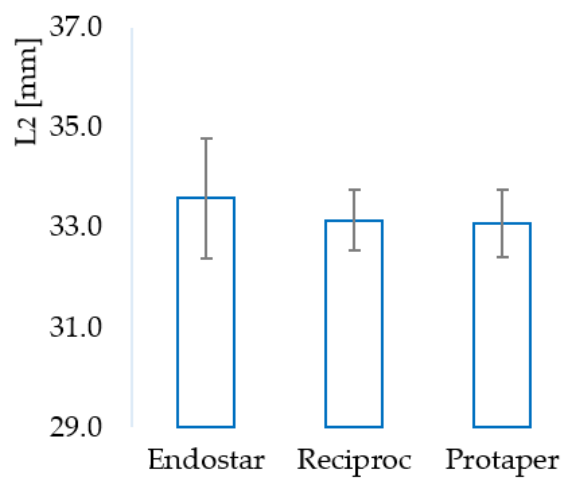

(a)

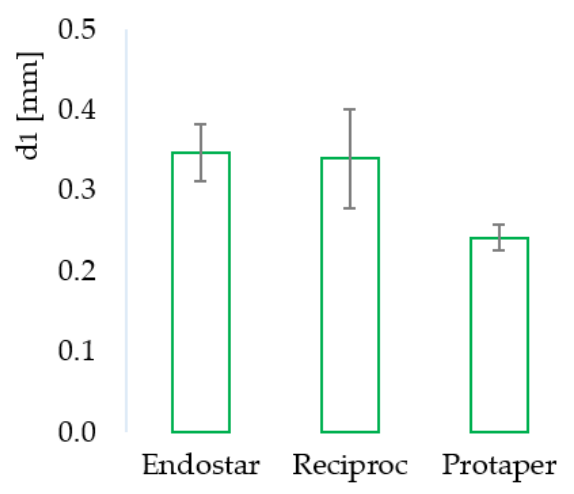

(b)

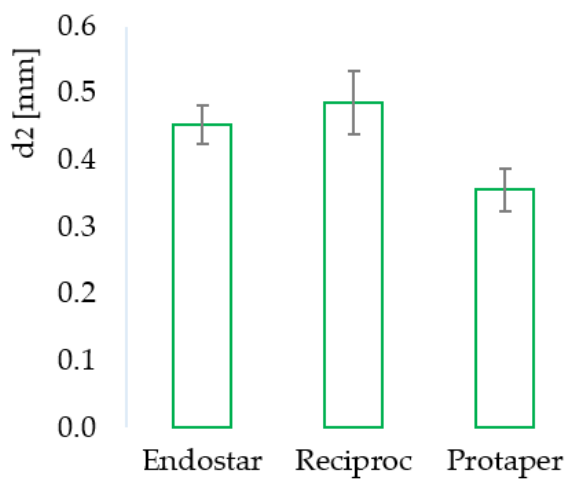

(c)

Figure 4. The measured dimensions of the instruments of each study group after fracture: (a) length $L_{2}(\mathrm{~mm}) ;(\mathbf{b}) \mathrm{minimum}$ $d_{1}(\mathrm{~mm})$ and $(\mathrm{c})$ maximum $d_{2}(\mathrm{~mm})$ dimension of the fracture section.

By comparing the total length of each type of instruments $\left(L_{1}\right)$ with their length after fracture $\left(L_{2}\right)$, it can be observed that the broken element has a length of 2 to $3 \mathrm{~mm}$ (with a higher average, of $3.24 \mathrm{~mm}$ for the Protaper instruments). Therefore, they correspond to the lower third of the instrument. This confirms the clinical experience of instruments failure inside the root canals or in simulated root canals from polycarbonate training blocks [26]. In addition, it can be observed from Figure $4 a$ that the fracture length of all three types of instruments included in the study are comparable, with dimensional variations of around $0.5 \mathrm{~mm}$.

Regarding the minimum $\left(d_{1}\right)$ and the maximum dimension $\left(d_{2}\right)$ of the cross sections, the statistical results concerning all considered instruments in the three study groups are presented in Figure $4 b$,c. In the following, these data are correlated with microscopic images to determine the geometrical properties of the sections after fracture.

After torsional loading, the diagrams of the torsion torque versus the twisting angle for each instrument of each group were drawn. This type of approach is necessary for this 
study to highlight the different behavior of instruments inside each group, because of the variations in the fracture lengths. The diagrams present the behavior of each instruments in the elastic zone, but also the maximum moment of torsion recorded at fracture point (Figure 5). The recorded values of these maximum torsional torques and twist angles, both corresponding to the fracture points (also for each of the fifteen instruments) are presented in Table 1.

The variability of the measurement results for a certain type of instrument are caused by the different gripping points in relation to the specific taper of the instruments. Thus, for griping tip lengths closer to $2 \mathrm{~mm}$, fractures occur at smaller torque values and twisting angles as compared to gripping lengths closer to $3 \mathrm{~mm}$. Thus, clinical situations corresponding to a range of gripping lengths are actually simulated, because this is what real-life situations refer to. Regarding the limits of this considered gripping lengths, the lower one corresponds to the situation in which the blockage on the root canal occurs in the first $2 \mathrm{~mm}$ of the instrument, while the higher one to the situation in which the first $3 \mathrm{~mm}$ of the active part of the instrument get stuck into the root canal.

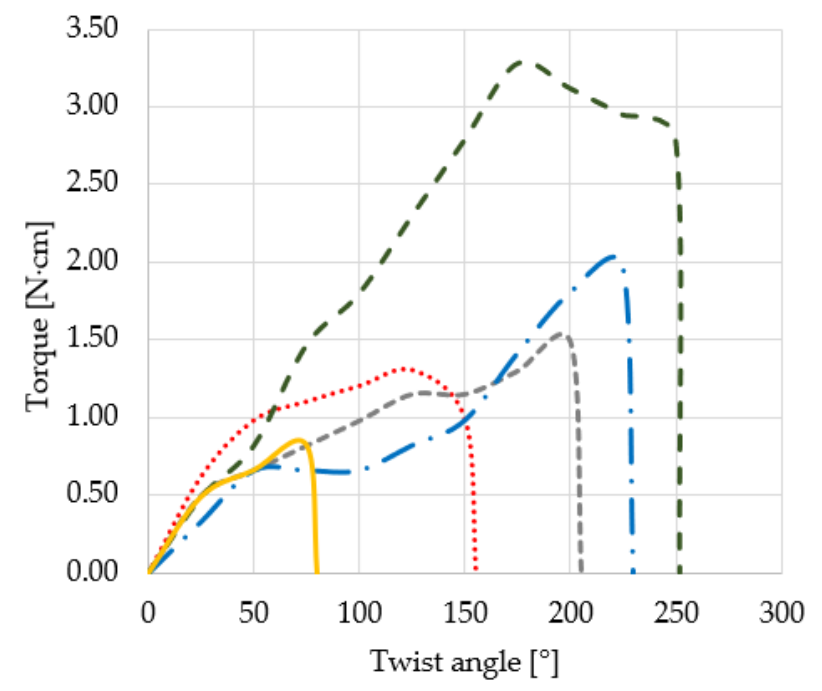

(a)

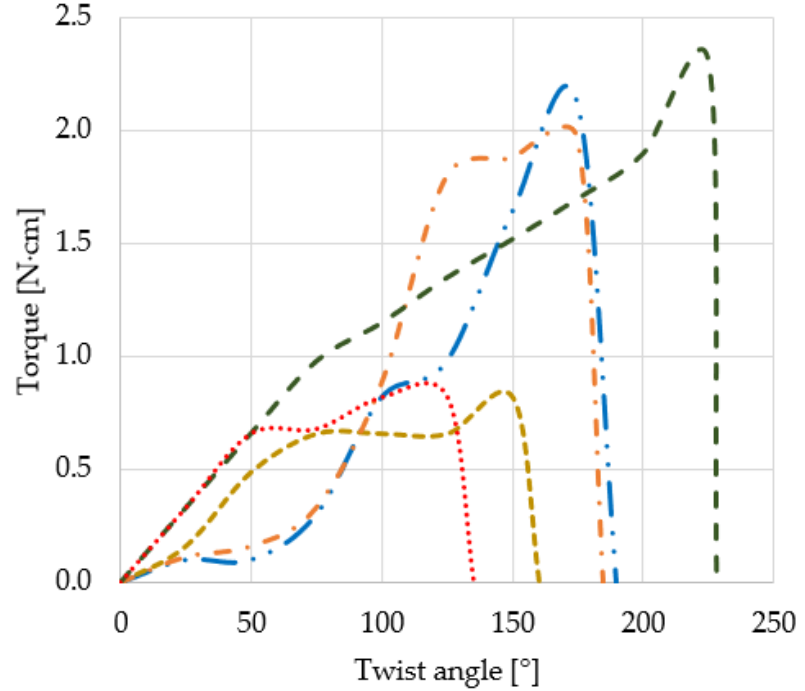

(b)

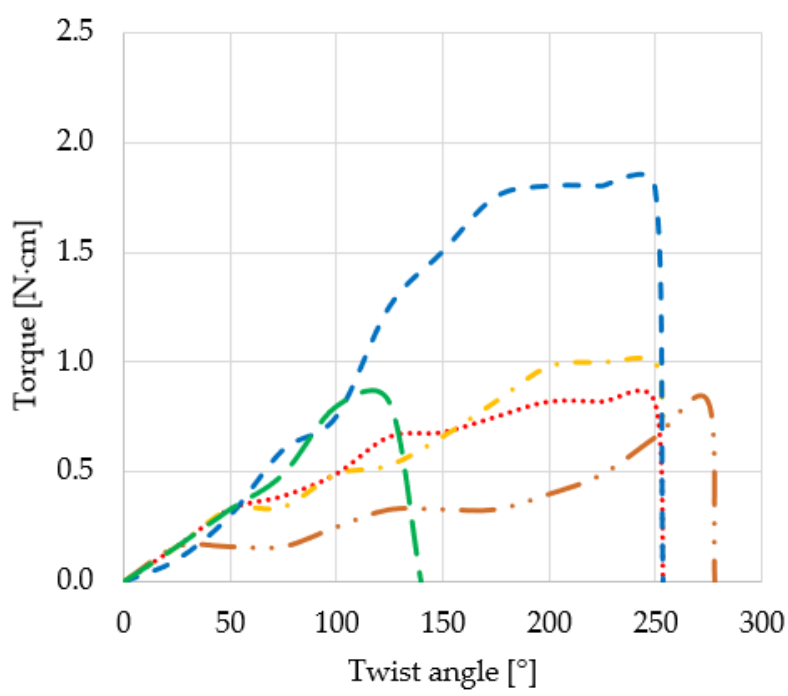

(c)

Figure 5. The diagrams of the torsion torque $T(\mathrm{~N} \cdot \mathrm{cm})$ versus the twisting angle $\theta\left(^{\circ}\right)$ determined for the samples of (a) Group Endostar, (b) Group Reciproc, and (c) Group Protaper. 
Table 1. Measured values of the torsional torque $T_{\max }$ and twisting angle $\theta_{\max }$ at fracture point for each instrument of the three study groups-according to Figure 5.

\begin{tabular}{ccccccc}
\hline \multirow{2}{*}{ Sample } & \multicolumn{2}{c}{ Group Endostar } & \multicolumn{2}{c}{ Group Reciproc } & \multicolumn{2}{c}{ Group Protaper } \\
\cline { 2 - 6 } & $\boldsymbol{T}_{\max }(\mathbf{N} \cdot \mathbf{c m})$ & $\boldsymbol{\theta}_{\max }\left(^{\circ}\right)$ & $\boldsymbol{T}_{\max }(\mathbf{N} \cdot \mathbf{c m})$ & $\left.\boldsymbol{\theta}_{\max } \mathbf{(}^{\circ}\right)$ & $\boldsymbol{T}_{\max }(\mathbf{N} \cdot \mathbf{c m})$ & $\boldsymbol{\theta}_{\max }\left({ }^{\circ}\right)$ \\
\hline 1 & 1.30 & 125 & 2.13 & 175 & 0.82 & 275 \\
2 & 1.48 & 200 & 0.82 & 150 & 0.82 & 250 \\
3 & 0.82 & 75 & 1.97 & 225 & 1.00 & 250 \\
4 & 3.28 & 175 & 2.30 & 125 & 0.82 & 125 \\
5 & 1.97 & 225 & 0.82 &
\end{tabular}

From Table 1, in the case of Group Endostar, the values of the maximum torsion torque $T_{\max }$ are superior, i.e., closer to $2 \mathrm{~N} \cdot \mathrm{cm}$. In comparison, the maximum reached torque of the Group Protaper instruments is $1 \mathrm{~N} \cdot \mathrm{cm}$. The angles $\theta_{\max }$ at which the fracture occurs range from 150 to $200^{\circ}$; they indicate the energy required to fracture the instruments by torsional load.

The statistics for the maximum reached torsion torques $T_{\max }$ and twisting fracture angle $\theta_{\max }$ for each type of instrument are obtained from Table 1 and are presented in Figure 6 . Insignificant differences can be remarked between the three study groups both in the case of maximum torque-for which Endostar values are insignificantly increased (Kruskal-Wallis test, $p=0.284$ ), and in the case of maximum twist-for which Protaper values are insignificantly increased (Kruskal-Wallis test, $p=0.108$ ).

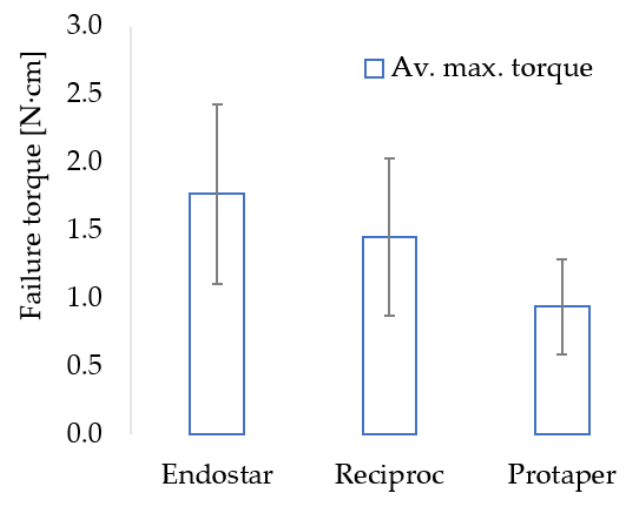

(a)

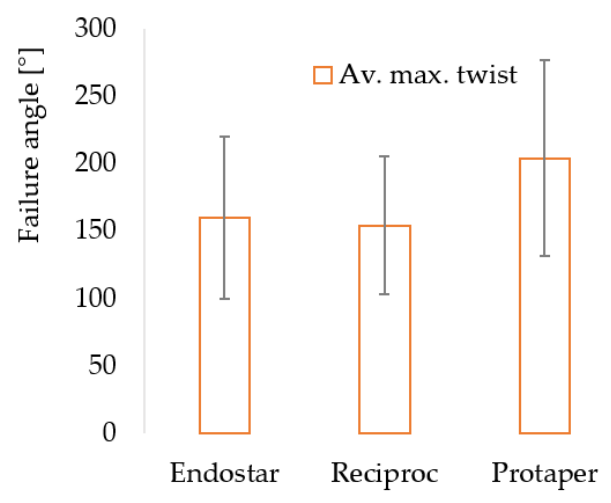

(b)

Figure 6. (a) The maximum (failure) torsion torque $T_{\max }$ and (b) the twisting angle $\theta_{\max }$ at fracture for the instruments of the three groups: Endostar, Reciproc, and Protaper.

This allows for ranking the mechanical behavior of the different available instruments in case of blocking their tip. The higher torque values $T_{\max }$ for the Endostar instruments, at a smaller values of the twisting angle $\theta_{\max }$ shows a good mechanical strength of these instruments, but also a brittle behavior. On the contrary, the Protaper instruments have a ductile character at fracture (as shown by the higher values of $\theta_{\max }$ ) but lower values of the mechanical strength (as shown by the smaller values of $T_{\max }$ ). The Reciproc instruments are in-between the two other types, with satisfactory (but not outstanding) values regarding both investigated parameters.

To observe the sections aspect and thus to be able to calculate the shear stresses, microscopic investigations of the fracture sections for each type of instrument were performed. They are presented in Figure 7 for an example from each group, with the remark that images obtained for all instruments in each group are similar. 


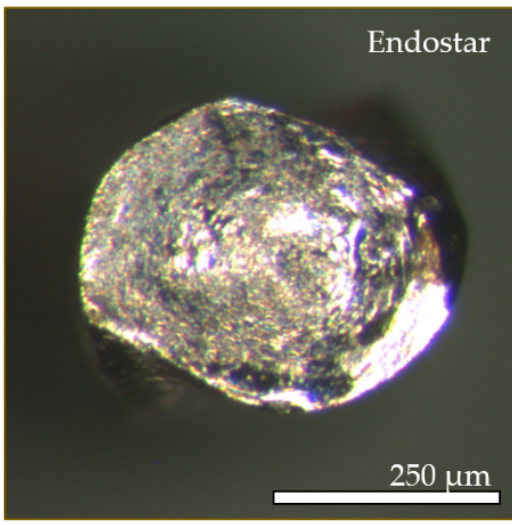

(a)

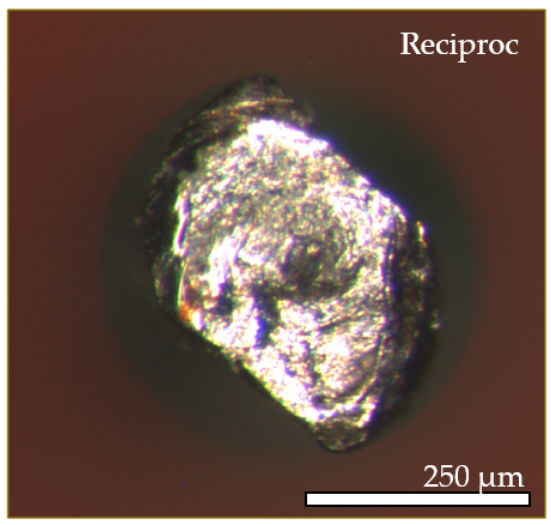

(b)

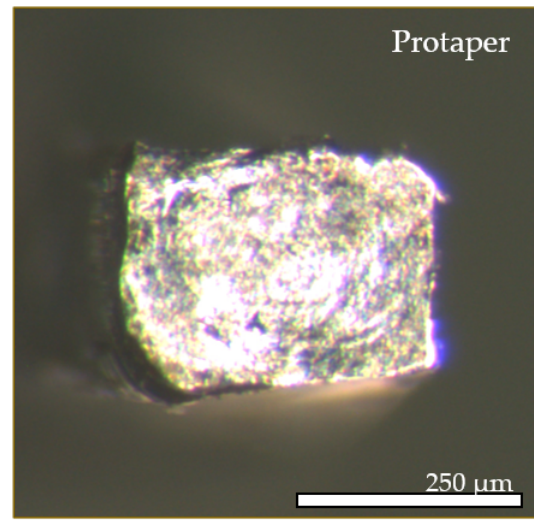

(c)

Figure 7. Fractography of the endodontic instruments: (a) Endostar E3, (b) Reciproc R 25, and (c) Protaper-Next X2 (i.e., an example from each of the three groups)-study carried on with optical microscopy with a $50 \times$ magnification.

In these microscopic images the aspect of the structure in the fracture section of each instrument can be seen, as well as the differences in size and shape of each instrument. The crystalline shiny aspect areas confirm fragile fracture zones, while the voids and the waves-type marks of the surface indicate ductile fracture caused by overloads. In addition, on every sample, traces of inter-crystalline slide with circular orientations characteristic to fracture by torsion can be observed. Regarding the capacity of the cross-section to withstand torsion, the optimal shape belongs to Endostar instruments, as they have the most circularlike shape from the three investigated groups. The shape of the cross-section of Protaper instruments is the most detrimental regarding torsion, as it is almost rectangular.

These aspects are further detailed in Figure 8, where the presentation starts from the initial shape of the three types of instruments (i.e., Endostar, Reciproc, and Protaper) in the first row, continues with their lateral aspect after fracture in the second row, and is finalized with the geometrical approximation of the fracture sections in the third row (all images being obtained with the optical microscope set at a $25 \times$ magnification).

The failure angle that can be observed in Figure $8(a 2, b 2, c 2)$ is not specific either to fragile fracture (as the section is not oblique on the longitudinal axis) nor to ductile fracture (as the section is not perpendicular on the longitudinal axis, either) for none of the three instruments. Therefore, the studied endodontic instruments can be considered similar from the ductile-fragile point of view.

The maximum tangential stresses $\tau_{\max }$ were determined using the values of the maximum torque $T_{\max }$ (Table 1 and Figure $6 \mathrm{a}$ ), as well as the approximate shape and dimensions obtained for every section of each instrument. The latter are presented in the third row of Figure 8, while their values were provided in Figure 4b,c.

From these values one may see that the Endostar instruments can be considered circular in their cross-section (Figure 8(a3)), therefore the maximum tangential stresses can be calculated with the well-known equation:

$$
\tau_{\max }=T_{\max } \cdot d / 2 I_{p}
$$

where $I_{p}=\pi \cdot d^{4} / 32$ is the polar moment of inertia of the cross-section, $d$ is the radius of the cross-section (Figure $4 b, c$ ), and $T_{\max }$ is the measured torsional torque at failure (Figure 6a).

The cross-sections of instruments Reciproc and Protaper can be considered rectangular (Figure $8(\mathrm{~b} 3, \mathrm{c} 3))$, therefore the equation of the tangential stress is:

$$
\tau_{\max }=T_{\max } / W_{t}
$$


where $W_{t}=k \cdot d_{1} \cdot d_{2}^{2}$ is the torsion modulus of strength, while $k=f\left(d_{1} / d_{2}\right)$ is the parameter that takes into consideration the dimensional ratio of the section; the minimum and maximum dimensions $d_{1}$ and $d_{2}$ are measured from the microscopy images in Figure 8(b3,c3) for Groups Reciproc and Protaper, respectively (as provided in Figure 4b,c).

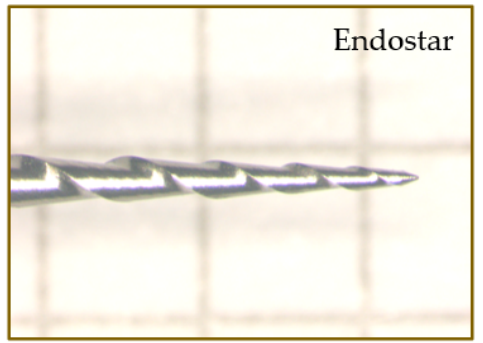

(a1)

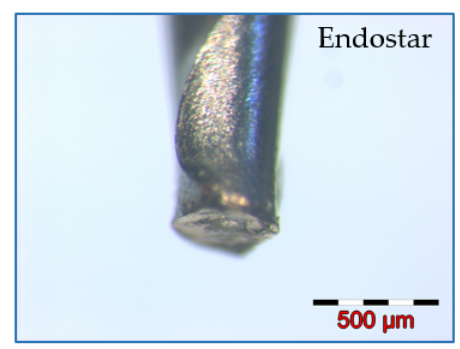

(a2)

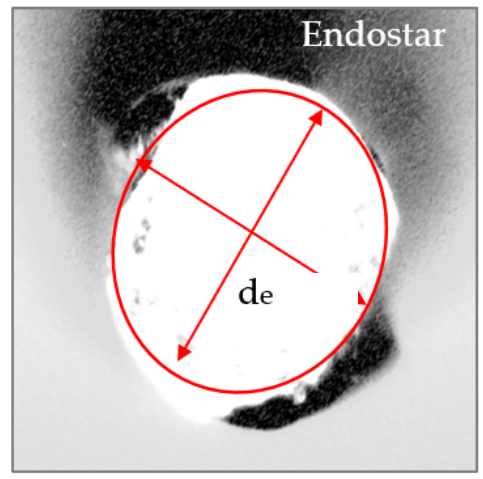

(a3)

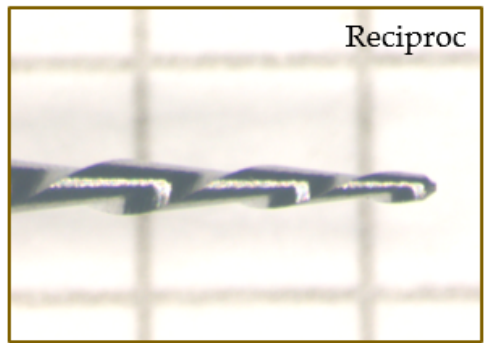

(b1)

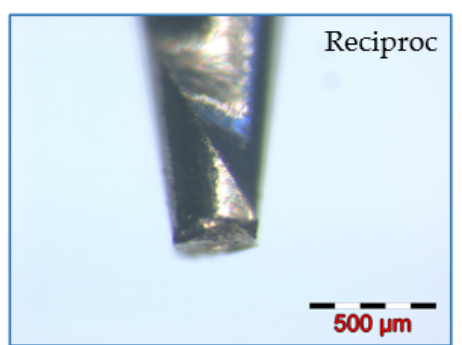

(b2)

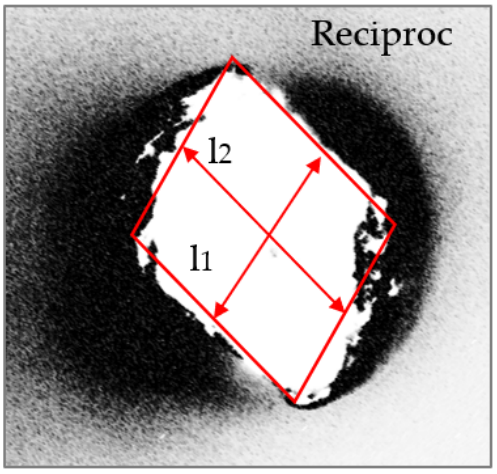

(b3)

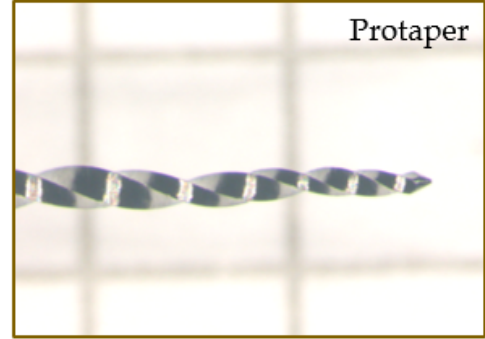

(c1)

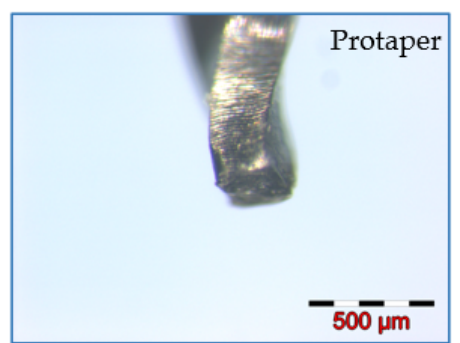

(c2)

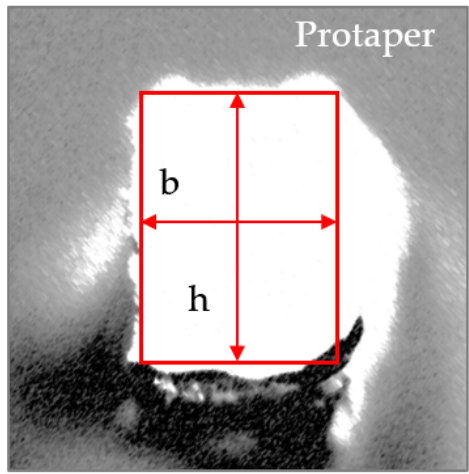

(c3)

Figure 8. (1) Initial longitudinal profile, (2) lateral aspect of the fracture site, and (3) geometrical approximation of the fracture sections for an example of instruments from each study group: (a) Endostar, (b) Reciproc, and (c) Protaper. All images were obtained with optical microscopy with a $25 \times$ magnification.

The calculated values of the maximum stress are presented in Table 2, considering also the standard deviations of the measured values. They are shown in parallel with the values of the maximum twist angle $\theta_{\max }$, corresponding to those presented in Figure $6 \mathrm{~b}$.

Table 2. Values of the maximum shear stresses $\tau_{\max }$ and of the twist angle $\theta_{\max }$ at fracture.

\begin{tabular}{ccccccc}
\hline & \multicolumn{2}{c}{ Group Endostar } & \multicolumn{2}{c}{ Group Reciproc } & \multicolumn{2}{c}{ Group Protaper } \\
\cline { 2 - 7 } & Mean & $\begin{array}{c}\text { Standard } \\
\text { Deviation }\end{array}$ & Mean & $\begin{array}{c}\text { Standard } \\
\text { Deviation }\end{array}$ & Mean & $\begin{array}{c}\text { Standard } \\
\text { Deviation }\end{array}$ \\
\hline$\tau_{\max }(\mathrm{MPa})$ & 1306.8 & 301.9 & 1160.0 & 473.0 & 1050.6 & 287.4 \\
$\theta_{\max }\left({ }^{\circ}\right)$ & 161.2 & 60.2 & 154.2 & 51.0 & 204.2 & 82.8 \\
\hline
\end{tabular}


Statistical processing was performed by SPSSv17. For numeric variables average values, standard deviations, minimum and maximum values were calculated. The comparisons between the numerical series were performed with the non-parametric KruskalWallis test for more than two series and with the Mann-Whitney test for comparisons between two sets of values with no Gaussian distribution. Insignificant differences were remarked between the three study groups both for $\tau_{\max }$-for which the Endostar values are insignificantly increased (Kruskal-Wallis test, $p=0.207$ ), and for $\theta_{\max }$-for which the Protaper values are insignificantly increased (Kruskal-Wallis test, $p=0.287$ ).

One may see that the values of both shear stress and twist angle in Table 2 have large standard deviations, because of the different fracture points: closer to $2 \mathrm{~mm}$ or to $3 \mathrm{~mm}$ from the tip of the instrument. For the former fracture length, the values of both torque and twist angle are smaller, while for the latter length they are higher-as pointed out regarding the individual values presented in Table 1 and Figure 5. This is due to the instrument shape and conicity. This imposes a separate analysis for the two lengths of the tip in the root canal. Therefore, to achieve a relevant comparison between the three considered groups, in Figure 9 we considered separately the instruments that broke closer to $2 \mathrm{~mm}$ from the tip (a) and those that broke closer to $3 \mathrm{~mm}$ from the tip (b) - from each group. One can remark that the spread of values of both shear stress and twist angle is higher for the former than for the latter case.

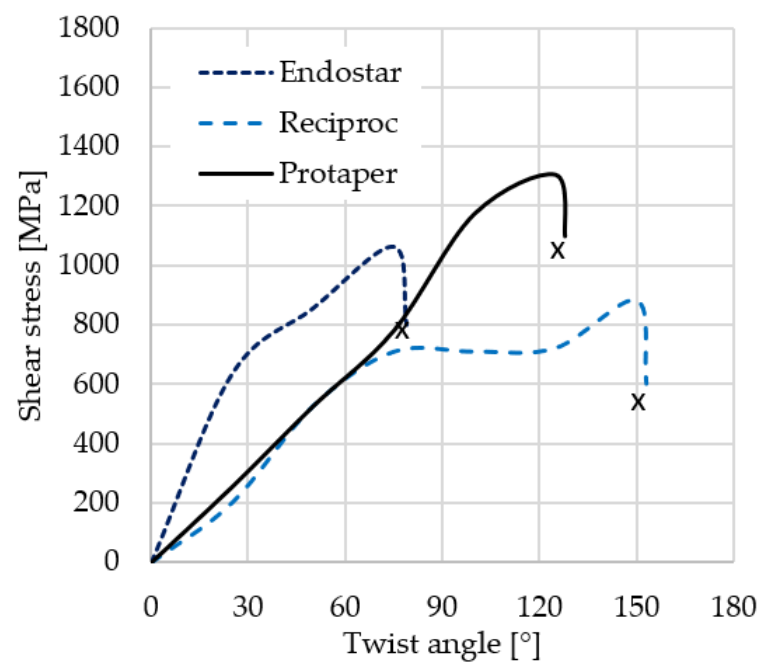

(a)

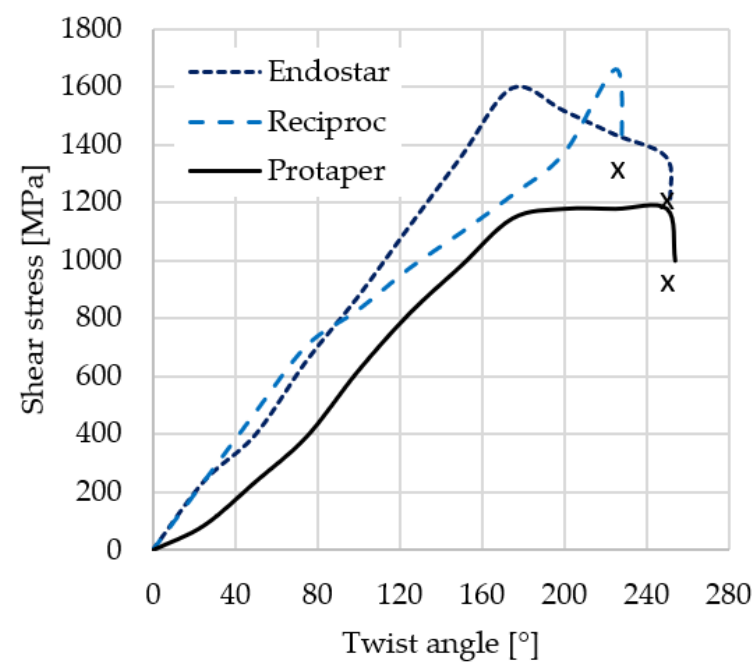

(b)

Figure 9. Shear stresses $\tau_{\max }$ versus twist angles $\theta$ of the Endostar, Reciproc and Protaper instruments: graphs obtained for samples that experience (a) low and (b) high torque and twist angle at failure.

However, by comparing the shear stress results from Figure 9, we may conclude that the results of all considered instruments are not as different as when comparing the obtained torque values at failure. Thus, the values and trends are similar for all three groups of instruments, which means that the disadvantage of the cross-section shape for Reciproc and Protaper instruments is compensated either by of their size or by the characteristics of their materials.

\section{Discussion}

Numerous studies have approached various aspects regarding the behavior of endodontic instruments, including the influence of lubricants on torsional loads [27], metallurgical features [28], comparison between manual instruments and NiTi files [29], influence of heat sterilization procedures [30] or of surface design [31]. During root canal preparation, endodontic instruments are exposed to torsional and flexural stresses, the former for straight root canals and the latter for curved ones [32]. These stresses contribute to 
metal fatigue and failure [33]. Few studies have looked into the impact of cyclic fatigue preloading on torsional resistance $[10,34,35]$ or into the impact of torsional preloads on cyclic fatigue resistance of traditional NiTi instrument [36-38].

In the present study, the effect of cyclic fatigue of three root canal type of instruments (and preparations) was considered, and then the maximum shear stresses obtained by torsion to failure of these (used) instruments were compared. In comparison to other studies, we did not consider the cycle fatigue in a dynamic regime [11], but rather in a static model [39]. While in other studies the simulated root canals were manufactured from stainless steel [40], in the present study, they were made from polycarbonate blocks. The first group of instruments is made out of conventional NiTi alloy (i.e., Endostar), while the other two groups of instruments are made of M-wire alloy (i.e., Reciproc and Protaper). The difference between the two systems made of M-wire alloy is the movement that the instrument develops inside the root canal, namely: Reciproc instruments use a reciprocating movement, while Protaper instruments uses a continuous rotational movement, similar to Endostar instruments.

Torsional behavior of NiTi instruments can be affected by a variety of factors, including root canal anatomy, instrument size, taper, geometry, alloy chemical composition, and the thermomechanical method used during manufacturing [41]. The torsion test was used in the analysis performed in this work to determine maximum torsional strength and angle of twisting before failure (and after instrument wear in processing five simulated root canals). The 2 to $3 \mathrm{~mm}$ tips of the instruments were fastened in the chuck of the machine, and rotations in a clockwise direction were performed [42-46].

In previous studies, instruments with larger metal mass-volume and tip diameter have been found to have higher torsional strength and lower rotation angles to failure. The taper, cross-sectional shape and tip diameter of the instruments have been demonstrated to have a direct impact on the metal mass-volume [43,45,47-49].

Comparing the lengths of the considered instruments after fracture $\left(L_{2}\right.$, Figure $\left.4 a\right)$ to the total/initial lengths $\left(L_{1}\right.$, Figure $\left.2 \mathrm{a}\right)$, it can be observed that the broken element has roughly a 2 to $3 \mathrm{~mm}$ length range. Thus, it belongs to the tip of the instrument. This confirms the clinical experience of rupture of instruments in dental canals or in the simulated root canals of polycarbonate blocks. In addition, it can be seen in Figure 4a that the breaking lengths of all the three types of instruments included in this experimental study are comparable, and that dimensional deviations of around $0.5 \mathrm{~mm}$ are obtained.

Regarding the diameters of the instruments, Peters et al. tested ProFile.04 tapered instruments for torsional stress and discovered that larger-diameter instruments had better torsional fatigue resistance [50]. Bahia et al. checked various tip sizes of ProFile.04 and .06 tapered files that had already been strained by cyclic fatigue (as considered in the present study, as well). The torsional stress of these pre-stressed files was tested, and it was discovered that files with larger diameters were more torsional load resistant [44].

As torsional stress behavior is often affected by cross-sectional design configuration, Berutti et al. used a mathematical model to simulate torsional and bending forces in two separate cross-sectional designs [51]. This consideration was also highlighted in the present study, where the optimal form is found to be that of instrument Endostar, which has the closer to circular shape of the fractured section from all three types of investigated instruments (as shown in Figure 8(a3), with values provided in Figure 4b,c). In contrast, the shape of the Protaper instruments is the most disadvantageous regarding torsional loadings, as it is almost rectangular in their cross-section after fracture (as shown in Figure 8c3, with values provided in Figure $4 b, c)$.

When comparing reciprocating NiTi instruments to continuous rotary motion, most studies assumed that reciprocating NiTi instruments were superior $[52,53]$. While comparing movements was not an aim of the present study, the instruments of Group Reciproc (which perform a reciprocating movement) were found to be slightly superior to those of Group Protaper (which use a continuous rotational movement), therefore the above theory was confirmed by the present study, as well. 
The fatigue tolerance of endodontic files can be affected by metal modifications or procedures, as well as by other manufacturing methods. Prior to usage, Kim et. al. examined surface characteristics and associated them with fracture strength. They discovered that files with a lot of machining grooves were more prone to cyclic fatigue fracture. Spiral milling cutting flutes into NiTi blanks is how most NiTi files are produced [54]. This was confirmed in the present study, as well.

In the concluding part of the present work, the values of shear stresses were found to be quite similar for the three groups of instruments-but considering in the analysis the variations in fracture lengths of instruments within the same study group. This means that the disadvantage given by the shape per section for the Reciproc and Protaper instruments are compensated either by size or by the intrinsic properties of the material from which they are made.

While this conclusion seems to level things for users, following this experimental study, technical recommendations can be extracted for current practice: if a blockage of the first 2 to $3 \mathrm{~mm}$ part of the tip in the root canal can be anticipated (by the excessive curving of the tip of the instrument), it is highly recommended that the handpiece is adjusted to torque values that do not exceed 1.5 to $2.5 \mathrm{~N} \cdot \mathrm{cm}$ for Endostar instruments. However, in case of such a blockage of the first 2 to $3 \mathrm{~mm}$ of the tip in the root canal, it is recommended that the handpiece is set to torque values that do not exceed 1 to $2 \mathrm{~N} \cdot \mathrm{cm}$ for Reciproc or Protaper instruments. From a clinical point of view, one has to stress that this can mean the difference between success and failure for the endodontic treatment, while failure means a fracture of the instrument inside the dental canal, therefore a loss of the tooth for the patient.

\section{Conclusions}

Following the comparative study performed, several conclusions can be drawn:

- The torsional behavior of all three types of instruments included in the present study is similar from the point of view of the maximum tangential stresses recorded.

- The fractographic analysis of the sections indicated that the failure mode of all three types of instruments is similar.

- From the perspective of withstanding torsional loads, the cross-sectional shape of E instruments is superior to the other two considered in the comparison.

- By improving the qualities of NiTi alloys, the deficiency due to the shape of the instrument design (i.e., cross-section) can be partially compensated.

- While the more robust instruments (Type E) appear to be more torsion-resistant, the others compensate through higher elasticity due to the M-wire alloy.

Thus, one can conclude that both hypotheses made in the Introduction were confirmed. Future work in this direction includes studies of cross-sections and instruments such as those considered in this work using scanning electron microscopy (SEM) [55], but also on-site optical coherence tomography (OCT) investigations, as we have demonstrated that the latter can replace the gold standard of SEM for the study of metallic fractures [56,57]. This also comes in the context that, due to its complementarity with the most common dental radiography, we have demonstrated that OCT is able to become part of current dental practice $[58,59]$.

Author Contributions: Conceptualization, A.-S.B.-P., C.S., V.-F.D., M.-L.N., D.I.S. and L.M.N.; methodology, A.-S.B.-P., C.S., V.-F.D., D.I.S. and M.-L.N.; optical microscopy, D.I.S. and C.O.; sample preparation, A.-S.B.-P. and D.I.S.; sample testing, D.I.S.; data and statistical analysis, D.I.S. and C.O.; supervision and project administration, C.S. and V.-F.D.; writing-original draft, A.-S.B.-P., O.-A.V.-B., L.O., R.M.H. and V.-F.D.; writing-review and editing, V.-F.D., A.-S.B.-P. and D.I.S.; funding, V.-F.D. All authors have read and agreed to the published version of the manuscript.

Funding: This research was supported by the Romanian Ministry of Research, Innovation and Digitization, CNCS/CCCDI-UEFISCDI, project PN-III-P2-2.1-PED-2020-4423, within PNCDI III (http:/ /3om-group-optomechatronics.ro/, accessed on 1 June 2021). 
Data Availability Statement: Data supporting reported results can be obtained from A.-S.B.-P.

Acknowledgments: The evaluations were performed in the Department of Mechanics and Strength of Materials, "Politehnica" University of Timisoara, 1 Mihai Viteazu Ave., 300222 Timisoara, Romania. The support of Anca Tudor with the statistical analysis is gratefully acknowledged. This paper is based on a presentation prepared for the '1st International Conference-Advances in 3OM: OptoMechatronics, Opto-Mechanics, and Optical Metrology', 13-16 December 2021, Timisoara, Romania.

Conflicts of Interest: The authors declare no conflict of interest. The funders had no role in the design of the study; in the collection, analyses, or interpretation of data; in the writing of the manuscript, or in the decision to publish the results.

\section{References}

1. Dagna, A.; Poggio, C.; Beltrami, R.; Chiesa, M.; Bianchi, S. Cyclic fatigue resistance of three NiTi single-file systems after immersion in EDTA. Dentistry 2013, 4, 1000184.

2. Pirani, C.; Cirulli, P.P.; Chersoni, S.; Micele, L.; Ruggeri, O.; Prati, C. Cyclic fatigue testing and metallographic analysis of nickel-titanium rotary instruments. JOE 2011, 37, 1013-1016. [CrossRef]

3. Cheung, G.S.; Liu, C.S.Y. A retrospective study of endodontic treatment outcome between nickel-Titanium rotary and stainless steel hand filing techniques. J. Endod. 2009, 35, 938-943. [CrossRef]

4. Walia, H.M.; Brantley, W.A.; Gerstein, H. An initial investigation of the bending and torsional properties of nitinol root canal files. J. Endod. 1988, 14, 346-351. [CrossRef]

5. Shen, Y.; Riyahi, A.M.; Campbell, L.; Zhou, H.; Du, T.; Whang, Z.; Qian, W.; Haapasalo, M. Effect of a combination of torsional and cyclic fatigue preloading on the fracture behavior of K3 and K3XF instruments. J. Endod. 2015, 41, 526-530. [CrossRef]

6. Cheung, G.S. Instrument fracture: Mechanisms, removal of fragments, and clinical outcomes. Endod. Top. 2009, 16, 1-26. [CrossRef]

7. Pedull'a, E.; Grande, N.M.; Plotino, G.; Palermo, F.; Gambarini, G.; Rapisarda, E. Cyclic fatigue resistance of two reciprocating nickel—titanium instruments after immersion in sodium hypo-chlorite. Int. Endod. J. 2013, 46, 155-159. [CrossRef]

8. Sattapan, B.; Nervo, G.J.; Palamara, J.E.A.; Messer, H.H. Defects in rotary nickel-titanium files after clinical use. J. Endod. 2000, 26, 161-165. [CrossRef] [PubMed]

9. Serene, T.P.; Adams, J.D.; Saxena, A. Nickel-Titanium Instruments. Applications in Endodontics; Ishiyaku EuroAmerica, Inc.: St. Louis, MO, USA, 1995.

10. Ullmann, C.J.; Peters, O.A. Effect of cyclic fatigue on static fracture loads in ProTaper nickel-titanium rotary instruments. J. Endod. 2005, 31, 183-186. [CrossRef]

11. Palma, P.J.; Messias, A.; Cerqueira, A.R.; Tavares, L.D.; Caramelo, F.; Roseiro, L.; Santos, J.M. Cyclic fatigue resistance of three rotary file systems in a dynamic model after immersion in sodium hypochlorite. Odontology 2019, 107, 324-332. [CrossRef]

12. Yum, J.; Cheung, G.S.P.; Park, J.K.; Hur, B.; Kim, H.C. Torsional strength and toughness of nickel-titanium rotary files. J. Endod. 2011, 37, 382-386. [CrossRef] [PubMed]

13. Bhagabati, N.; Yadav, S.; Talwar, S. An in vitro cyclic fatigue analysis of different endodontic nickel-titanium rotary instruments. J. Endod. 2012, 38, 515-518. [CrossRef]

14. Plotino, G.; Grande, N.M.; Melo, M.C.; Bahia, M.G.; Testarelli, L.; Gambar-ini, G. Cyclic fatigue of NiTi rotary instruments in a simulated apical abrupt curvature. Int. Endod. J. 2010, 43, 226-230. [CrossRef]

15. Goldberg, M. Centering ability and influence of experience when using wave one single-file technique in simulated canals. Int. J. Dent. 2012, 2012, 206321. [CrossRef]

16. Yufei, L.; Ning, Q.; Ming, X.; Chuyu, W.; Xiaoqing, Y. Comparison of shaping ability of five nickel-titanium rotary instruments in simulated curved canals. J. Dent. Oral Health 2017, 5, 2.

17. Martin, B.; Zelada, G.; Varela, P.; Bahillo, J.G.; Magán, F.; Ahn, S.; Rodríguez, C. Factors influencing the fracture of nickel titanium rotary instruments. Int. Endod. J. 2003, 36, 262-266. [CrossRef] [PubMed]

18. Alapati, S.; Brantley, W.A.; Iijima, M.; Clark, W.A.; Kovarik, L.; Buie, C.; Liu, J.; Ben Johnson, W. Metallurgical characterization of a new nickel-titanium wire for rotary endodontic instruments. J. Endod. 2009, 35, 1589-1593. [CrossRef]

19. Ninan, E.; Berzins, D.W. Torsion and bending properties of shape memory and superelastic nickel-titanium rotary instruments. J. Endod. 2013, 39, 101-104. [CrossRef] [PubMed]

20. Gambarini, G.; Grande, N.M.; Plotino, G.; Somma, F.; Garala, M.; De Luca, M.; Testarelli, L. Fatigue resistance of engine-driven rotary nickel-titanium instruments produced by new manufacturing methods. J. Endod. 2008, 34, 1003-1005. [CrossRef]

21. Sekar, V.; Kumar, R.; Nandini, S.; Ballal, S.; Velmurugan, N. Assessment of the role of cross section on fatigue resistance of rotary files when used in reciprocation. Eur. J. Dent. 2016, 10, 541-545. [CrossRef]

22. Medha, A.; Patil, S.; Hoshing, U.; Bandekar, S. Evaluation of forces generated on three different rotary files systems in apical third of root canal using finite element analysis. J. Clin. Diagn. Res. 2014, 8, 243-246. [CrossRef]

23. Galal, M.; Hamdy, T.M. Evaluation of stress distribution in nickel-titanium rotary instruments with different geometrical designs subjected to bending and torsional load: A finite element study. Bull. Natl. Res. Cent. 2020, 44, 121. [CrossRef] 
24. Seracchiani, M.; Miccoli, G.; Di Nardo, D.; Zanza, A.; Cantore, M.; Gambarini, G.; Testarelli, L. Effect of flexural stress on torsional resistance of NiTi instruments. J. Endod. 2020, 3, 118. [CrossRef]

25. Sarul, M.; Kozakiewicz, M.; Jurczyszyn, K. Surface evaluation of orthodontic wires using texture and fractal dimension analysis. Materials 2021, 14, 3688. [CrossRef] [PubMed]

26. Altunbas, D.; Kutuk, B.; Kustarci, A. Shaping ability of reciprocating single-file and full-sequence rotary instrumentation systems in simulated curved canals. Eur. J. Dent. 2015, 9, 346-351. [CrossRef]

27. Mazzoni, A.; Pacifici, A.; Zanza, A.; Giudice, A.D.; Reda, R.; Testarelli, L.; Gambarini, G.; Pacifici, L. Assessment of real-time operative torque during nickel-titanium instrumentation with different lubricants. Appl. Sci. 2020, 10, 6201. [CrossRef]

28. Generali, L.; Malovo, A.; Bolelli, G.; Borghi, A.; La Rosa, G.R.M.; Puddu, P.; Lusvarghi, L.; Rota, A.; Consolo, U.; Pedullà, E. Mechanical properties and metallurgical features of new green NiTi reciprocating instruments. Materials 2020, 13, 3736. [CrossRef]

29. Alovisi, M.; Dioguardi, M.; Carossa, M.; Troiano, G.; Domini, M.C.; Paolino, D.S.; Chiandussi, G.; Berutti, E. Working length transfer in the endodontic clinical practice: A comparative study. Appl. Sci. 2020, 10, 5824. [CrossRef]

30. Dioguardi, M.; Crincoli, V.; Laino, L.; Alovisi, M.; Laneve, E.; Sovereto, D.; Raddato, B.; Zhurakivska, K.; Mastrangelo, F.; Ciavarella, D.; et al. Surface alterations induced on endodontic instruments by sterilization processes, analyzed with atomic force microscopy: A systematic review. Appl. Sci. 2019, 9, 4948. [CrossRef]

31. Gambarini, G.; Miccoli, G.; Seracchiani, M.; Khrenova, T.; Donfrancesco, O.; D’Angelo, M.; Galli, M.; Di Nardo, D.; Testarelli, L. Role of the flat-designed surface in improving the cyclic fatigue resistance of endodontic NiTi rotary instruments. Materials 2019, 12, 2523. [CrossRef]

32. Thu, M.; Ebihara, A.; Adel, S.; Okiji, T. Analysis of torque and force induced by rotary nickel-titanium instruments during root canal preparation: A systematic review. Appl. Sci. 2021, 11, 3079. [CrossRef]

33. Endal, U.; Shen, Y.; Knut, A.; Gao, Y.; Haapasalo, M. A high-resolution computed tomographic study of changes in root canal isthmus area by instrumentation and root filling. J. Endod. 2011, 37, 223-227. [CrossRef]

34. Kim, J.Y.; Cheung, G.S.; Park, S.H.; Ko, D.C.; Kim, J.W.; Kim, H.C. Effect from cyclic fatigue of nickel-titanium rotary files on torsional resistance. J. Endod. 2012, 38, 527-530. [CrossRef] [PubMed]

35. Campbell, L.; Shen, Y.; Zhou, H.M.; Haapasalo, M. Effect of fatigue on torsional failure of nickel-titanium controlled memory instruments. J. Endod. 2014, 40, 562-565. [CrossRef]

36. Bahia, M.G.; Melo, M.C.; Buono, V.T. Influence of cyclic torsional loading on the fatigue resistance of K3 instruments. Int. Endod. J. 2008, 10, 883-891. [CrossRef] [PubMed]

37. Cheung, G.S.; Oh, S.H.; Ha, J.H.; Kim, S.K.; Park, S.H.; Kim, H.C. Effect of torsional loading of nickel-Titanium instruments on cyclic fatigue resistance. J. Endod. 2013, 39, 1593-1597. [CrossRef]

38. Galvao Barbosa, F.O.; Ponciano Gomes, J.A.; Pimenta de Araujo, M.C. Influence of previous angular deformation on flexural fatigue resistance of K3 nickel-titanium rotary instruments. J. Endod. 2007, 33, 1477-1480. [CrossRef] [PubMed]

39. Sousa, J.; Basto, J.; Roseiro, L.; Messias, A.; dos Santos, J.M.; Palma, P. Avaliação da fadiga cíclica de 3 sistemas de limas utilizadas em instrumentação mecanizada. Revista Portuguesa de Estomatologia, Medicina Dentária e Cirurgia Maxilofacial 2015, 56, 239-245. [CrossRef]

40. La Rosa, G.R.M.; Shumakova, V.; Isola, G.; Indelicato, F.; Bugea, C.; Pedullà, E. Evaluation of the cyclic fatigue of two single files at body and room temperature with different radii of curvature. Materials 2021, 14, 2256. [CrossRef]

41. Melo, M.C.; Pereira, E.S.; Viana, A.C.; Fonseca, A.M.; Buono, V.T.; Bahia, M.G. Dimensional characterization and mechanical behaviour of K3 rotary instruments. Int. Endod. J. 2008, 41, 329-338. [CrossRef]

42. Pedullà, E.; Lo Savio, F.; Boninelli, S.; Plotino, G.; Grande, N.M.; La Rosa, G. Torsional and cyclic fatigue resistance of a new nickel-titanium instrument manufactured by electrical discharge machining. J. Endod. 2016, 42, 156-159. [CrossRef]

43. Alcalde, M.P.; Tanomaru-Filho, M.; Bramante, C.M.; Duarte, M.A.; Guerreiro-Tanomaru, J.M.; Camilo-Pinto, J.; Só, M.V.R.; Vivan, R.R. Cyclic and torsional fatigue resistance of reciprocating single files manufactured by different nickel-titanium alloys. J. Endod. 2017, 43, 1186-1191. [CrossRef]

44. Bahia, M.G.; Melo, M.C.; Buono, V.T. Influence of simulated clinical use on the torsional behavior of nickel-titanium rotary endodontic instruments. Oral Surg. Oral Med. Oral Pathol. Oral Radiol. Endod. 2006, 101, 675-680. [CrossRef]

45. Alcalde, M.P.; Duarte, M.A.; Bramante, C.M.; Tanomaru-Filho, M.; Vasconcelos, B.C.; Só, M.V.; Vivan, R.R. Torsional fatigue resistance of pathfinding instruments manufactured from several nickel-titanium alloys. Int. Endod. J. 2018, 51, 697-704. [CrossRef]

46. Berutti, E.; Negro, A.R.; Lendini, M.; Pasqualini, D. Influence of manual preflaring and torque on the failure rate of ProTaper rotary instruments. J. Endod. 2004, 30, 228-230. [CrossRef]

47. Goo, H.J.; Kwak, S.W.; Ha, J.H.; Pedullà, E.; Kim, H.C. Mechanical properties of various heat-treated nickel-titanium rotary instruments. J. Endod. 2017, 43, 1872-1877. [CrossRef]

48. Viana, A.C.; Melo, M.C.C.; Bahia, M.G.A.; Lopes Buono, V.T. Relationship between flexibility and physical, chemical, and geometric characteristics of rotary nickel-titanium instruments. Oral Surg. Oral Med. Oral Pathol. Oral Radiol. Endod. 2010, 110, 527-533. [CrossRef]

49. Baek, S.H.; Lee, C.J.; Versluis, A.; Kim, B.M.; Lee, W.; Kim, H.C. Comparison of torsional stiffness of nickel-titanium rotary files with different geometric characteristics. J. Endod. 2011, 37, 1283-1286. [CrossRef] [PubMed] 
50. Peters, O.A.; Barbakow, F. Dynamic torque and apical forces of ProFile.04 rotary instruments during preparation of curved canals. Int. Endod. J. 2002, 35, 379-389. [CrossRef] [PubMed]

51. Berutti, E.; Chiandussi, G.; Gaviglio, I.; Ibba, A. Comparative analysis of torsional and bending stresses in two mathematical models of nickel-titanium rotary instruments: ProTaper versus ProFile. J. Endod. 2003, 29, 15-19. [CrossRef]

52. Kim, H.C.; Kwak, S.W.; Cheung, G.S.; Ko, D.H.; Chung, S.M.; Lee, W.C. Cyclic fatigue and torsional resistance of two new nickel-titanium instruments used in reciprocation motion: Reciproc versus Wave One. J. Endod. 2012, 38, 541-544. [CrossRef]

53. Yared, G. Canal preparation using only one NiTi rotary instrument: Preliminary observations. Int. Endod. J. 2008, 41, 339-344. [CrossRef]

54. Kim, H.C.; Yum, J.; Hur, B.; Cheung, G.S. Cyclic fatigue and fracture characteristics of ground and twisted nickel-titanium rotary files. J. Endod. 2010, 36, 147-152. [CrossRef]

55. Drukteinis, S.; Peciuliene, V.; Bendinskaite, R.; Brukiene, V.; Maneliene, R.; Rutkunas, V. Shaping and Centering Ability, Cyclic fatigue resistance and fractographic analysis of three thermally treated NiTi endodontic instrument systems. Materials 2020, 13, 5823. [CrossRef]

56. Hutiu, G.; Duma, V.-F.; Demian, D.; Bradu, A.; Podoleanu, A. Surface imaging of metallic material fractures using optical coherence tomography. Appl. Opt. 2014, 53, 5912-5916. [CrossRef]

57. Hutiu, G.; Duma, V.-F.; Demian, D.; Bradu, A.; Podoleanu, A. Assessment of ductile, brittle, and fatigue fractures of metals using optical coherence tomography. Metals 2018, 8, 117. [CrossRef]

58. Erdelyi, R.-A.; Duma, V.-F.; Sinescu, C.; Dobre, G.; Bradu, A.; Podoleanu, A. Dental diagnosis and treatment assessments: Between $\mathrm{X}$-rays radiography and optical coherence tomography. Materials 2020, 13, 4825. [CrossRef]

59. Erdelyi, R.-A.; Duma, V.-F.; Sinescu, C.; Dobre, G.; Bradu, A.; Podoleanu, A. Optimization of X-ray investigations in dentistry using optical coherence tomography. Sensors 2021, 21, 4554. [CrossRef] 